\title{
Characteristics of the Sea-Breeze Circulation in the Pearl River Delta Region and Its Dynamical Diagnosis
}

\author{
CHeng You \\ Division of Environment and Sustainability, Hong Kong University of Science and Technology, Hong Kong, China \\ JIMMY CHI-HuNG FUNG \\ Division of Environment and Sustainability, and Department of Mathematics, Hong Kong University of \\ Science and Technology, Hong Kong, China
}

(Manuscript received 12 June 2018, in final form 6 December 2018)

\begin{abstract}
The Pearl River delta (PRD) region has experienced rapid economic development since the 1980s and has become one of the world's largest industrial zones and metropolitan areas. Previous studies have shown that the sea-breeze circulation can contribute to pollutant transportation and convective initiation, so it is useful to study the dynamic structure of the sea-breeze circulation in the PRD region. Many researchers have focused on the effects of environmental factors, such as topography, urbanization, and background wind, on the sea breeze, but most focused only on case studies and did not quantify the characteristics of the sea-breeze circulation climatologically. In this study, a sea-breeze identification metric was defined to identify sea-breeze events from WRF simulation data of 2012 and quantify their characteristics, including their start time, end time, strength, height, frequency, pumping ability, and inland-penetrating distance. The results indicate that this method works well to identify and quantify the sea-breeze events of 2012. It is found that the solenoid term, the largest positive contributor to vorticity acceleration, is mostly modulated by the temperature gradient. Therefore, the frontogenesis of the seabreeze front is discussed in this study. The result shows that offshore background wind that increases frontogenesis is favorable to the development of the sea breeze, but it also prevents it from propagating vertically and horizontally.
\end{abstract}

\section{Introduction}

The Pearl River delta (PRD) region is one of the three largest economic engines in China and one of the world's most significant manufacturing centers. This region encompasses several major cities, including Hong Kong, Guangzhou, Shenzhen, Zhuhai, Dongguan, Foshan, and Zhongshan, China, all of which are located near the coast. In summer, the southwesterly Asian summer monsoon prevails in the PRD region and brings humid and warm air into this region. In spring, the large-scale atmospheric circulation switches from a winter monsoon state to a summer monsoon state and, correspondingly, the prevailing wind shifts from northeasterly to southwesterly. In autumn, the summer monsoon has retreated, while the northeasterly winter monsoon gradually controls the

Corresponding author: Cheng You, cheng.you@misu.su.se
PRD region in later autumn and reaches its mature stage in winter.

The sea breeze that blows onshore on sunny days is driven by the temperature difference between land and sea (Simpson 1994). It can extend both onshore and offshore. In the PRD region, the estuary sea breeze penetrates $60-80 \mathrm{~km}$ inland (Ding et al. 2004). The depth of the sea breeze is usually $350 \mathrm{~m}$, and the mixed sea-air can reach a height of $700 \mathrm{~m}$ (Simpson 1994). The sea breeze can contribute to pollutant transport in this region. Liu et al. (2008) found that the nighttime sea breeze can bring aged aerosols back inland and increase the concentration of coarse particles. A stronger sea breeze can decrease the daytime accumulation of ozone and other air pollutants caused by the urban plume in the PRD region (Wang and Kwok 2003). However, Ding et al. (2004) found that a delayed sea breeze may lead to high concentrations of ozone in Hong Kong. Pollutants also can be trapped in the sea-breeze circulation in the PRD region (Lo et al. 2006; 


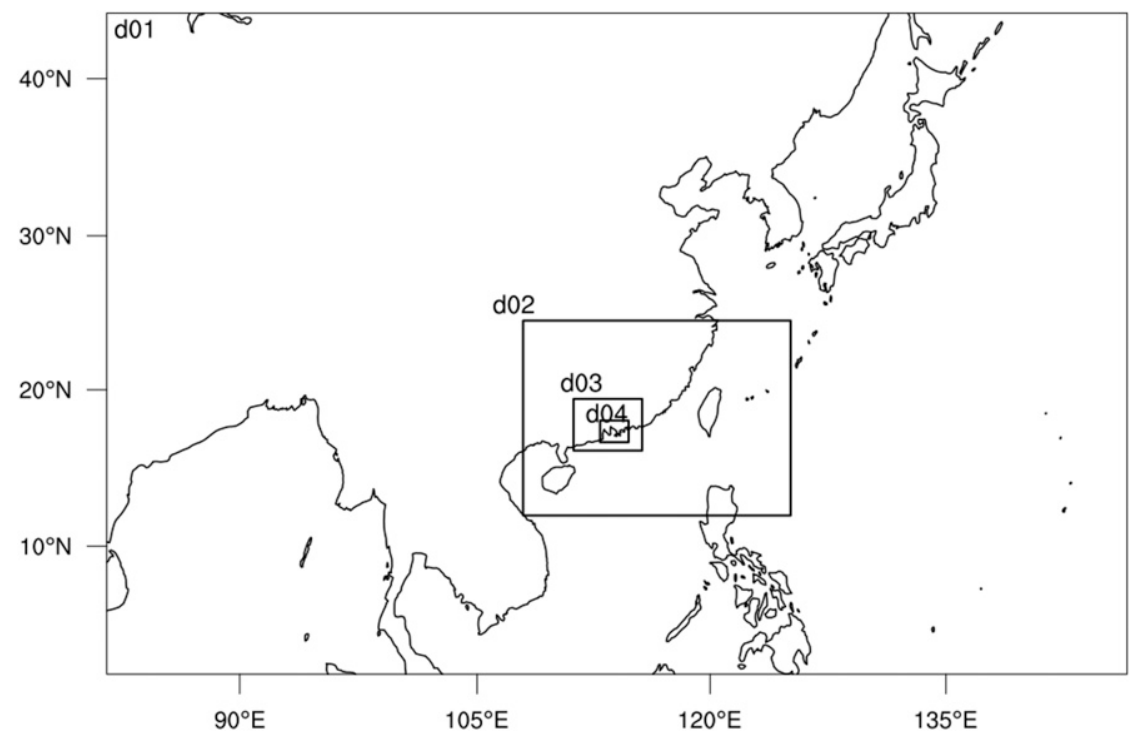

FIG. 1. Four domains used in the WRF simulation.

Wu et al. 2013). This trapping effect of the sea-breeze circulation contributes to the increase of ozone concentration in the PRD region (Lam et al. 2005). In the convergent zone of a sea breeze, a rapid vertical velocity brings tracer material to upper levels, which can reduce the near-surface concentration immediately (Thompson et al. 2007), but the lifted inversion layer above the convergent zone is also considered to be an important contributor to the regional haze problem in the PRD region (Huang et al. 2006).

Most investigations of sea breezes have focused on case studies. Although these studies have revealed some characteristics of several sea-breeze cases, their general features cannot be illustrated by these cases alone. In addition, these previous studies did not define any standard variables to quantify the onset time, cessation time, and the strength of sea breezes, which makes it difficult to compare sea-breeze events in different scenarios and regions.

A quantitative method is developed in section 2 of this paper to characterize sea-breeze events in the PRD region. The characteristics of the estuary sea breeze in the PRD region are discussed in section 3. The dynamical diagnosis of the sea-breeze circulation is introduced in section 4 , and section 5 concludes the paper.

\section{Data and methods}

\section{a. Data}

In this study, Weather Research and Forecasting (WRF) Model simulation data for 2012 are used to determine sea-breeze characteristics in Guangdong Province, China. The 1-yr simulation data (from 0000:00
UTC December 2011 to 0000:00 UTC 4 January 2013) are the integration of data from 121 separate simulations, each of which was a 4-day run with the first day's data scrapped for the spinup period. Four domains are utilized in this two-way nesting simulation, and they cover eastern Asia (d01), south China (d02), the PRD region (d03) and the Pearl River estuary (d04) (Fig. 1). The horizontal resolutions for these domains are $27,9,3$, and $1 \mathrm{~km}$, respectively. The WRF terrain-following coordinate contains 47 eta levels, and 17 levels are within $1 \mathrm{~km}$ above the surface. The Asymmetric Convective Model, version 2 (Pleim 2007a,b), is used in this simulation because it performs better than other planetary boundary layer schemes in the PRD region (Xie et al. 2012).

The WRF simulation for 2012 implements observation nudging in domains 3 and 4, by using a set of $10-\mathrm{m}$ wind observation that covers all of 2012, including data from numerous meteorological stations around Hong Kong, the Pearl River delta, and other areas of Guangdong Province. Although the abundance of meteorological observations can enhance WRF, not all observations are unconditionally applicable. The choice of applicable observation data is determined by several quality-control filters (error maximum test, buddy check test, spike removal, removal of superadiabatic lapse rates), after which the data are transformed to the WRF OBSGRID data format for WRF ingestion.

Independent surface observations are used to evaluate WRF performance. Table 1 summarizes the core statistical measures of wind used in the WRF evaluation for 2012. All the statistics are reasonable; for example, the wind speed index of agreement is 0.78 (Table 1), which indicates that most stations show good agreement 
TABLE 1. Validation of 2-m temperature and 10-m wind simulation by WRF. About 300 surface stations are used for the data validation. For the simulated mean, we interpolated the values to match observation station locations.

\begin{tabular}{lccccc}
\hline \hline & Observed mean & Simulated mean & Mean bias & Root-mean-square error & Index of agreement \\
\hline Wind speed $\left(\mathrm{m} \mathrm{s}^{-1}\right)$ & 4.03 & 3.89 & 0.89 & 1.93 & 0.78 \\
Temperature $\left({ }^{\circ} \mathrm{C}\right)$ & 22.15 & 23.55 & 1.41 & 2.57 & 0.94 \\
\hline
\end{tabular}

between the simulated WRF and its corresponding observations. WRF is able to simulate the wide range of diurnal minimum and maximum temperatures with an average index of agreement of 0.94 (Table 1). Overall, this is a very promising result for the WRF simulation (Emery et al. 2001).

\section{b. Definition of sea-breeze events}

One divergent center can always be found inside polygon ABCDEFG (Fig. 3b) when a sea-breeze event occurs. According to Gauss's law, the integrated divergence inside the polygon equals the wind flux over the sides of polygon ABCDEFG. Thus, the wind flux over polygon ABCDEFG (flux) in 2012 is evaluated, and its positive diurnal signals (Fig. 2a) that meet the following three requirements will be taken as the seabreeze divergent center in the PRD estuary (polygon ABCDEFG):

1) Sea-breeze events should be finished in 1 day.

2) When the solar energy at the top of atmosphere $S_{\text {top }}$ reaches its maximum, the sea-breeze events should already have occurred.

3) The first requirement should be met at heights of $50,100,150$, and $200 \mathrm{~m}$.

Sea breezes along each coast are evaluated only for days when sea-breeze divergent centers appear in the PRD estuary. During these days, horizontal wind fields at a height of $50 \mathrm{~m}$ are decomposed into two parts, divergent and nondivergent wind fields, with the wind decomposition method invented by Cao and Xu (2011) and Xu et al. (2011). Generally, a sea breeze is a typical divergent wind, and the large-scale background wind is nearly nondivergent. Therefore, the divergent velocity component is used to evaluate the intensity of a sea breeze, and the nondivergent velocity is considered background wind.

As shown in Fig. 3, three main coasts in the PRD region are simplified as straight lines $\mathrm{AG}, \mathrm{BC}$, and $\mathrm{DE}$. From our simulation results, a sea breeze-especially its divergent component in the PRD region-is mostly perpendicular to the coastlines. Therefore, the normal divergent velocity, normal nondivergent velocity, and normal original velocity are spatially averaged along these three coasts and are marked as $V_{D}, V_{B}$, and $V_{O}$, respectively. Positive signals of $V_{D}$ (Fig. 2b) are taken as sea-breeze events along each coast if the following requirements are met:

1) Sea-breeze events should start after sunrise.

2) Sea-breeze events should be finished in 1 day.

3) When $S_{\text {top }}$ reaches its maximum, the sea-breeze events should have already occurred.

4) Both $V_{D}$ and $V_{O}$ should be positive (onshore).

For sea-breeze events highlighted in Fig. 2b, the start time is defined as the time when $V_{D}$ and $V_{O}$ are both positive, whereas the time when any of them decreases below 0 is taken as the end time of the sea-breeze event. The $V_{D}$ at the first level (i.e., at $50 \mathrm{~m}$ ) is taken as the intensity of the sea breeze.

\section{c. Height of sea breeze and its pumping ability}

The horizontal original velocities at all vertical levels in domain 4 are projected to $V$ in the direction perpendicular to the coast. In the projected wind field, taking coast $A G$ as an example, vertical cross sections are collected from $A_{1} A_{2}$ to $G_{1} G_{2}$ (Fig. 3a) at 1-km intervals and averaged along coast AG. In the averaged cross section (Fig. 4), the height at which $V$ over the coast changes from positive to negative for the first time is considered as the height of the sea breeze $H_{\mathrm{SB}}$. Although the depths of the sea breeze (positive $V$ ) vary with the location and $H_{\mathrm{SB}}$ is not the maximum among

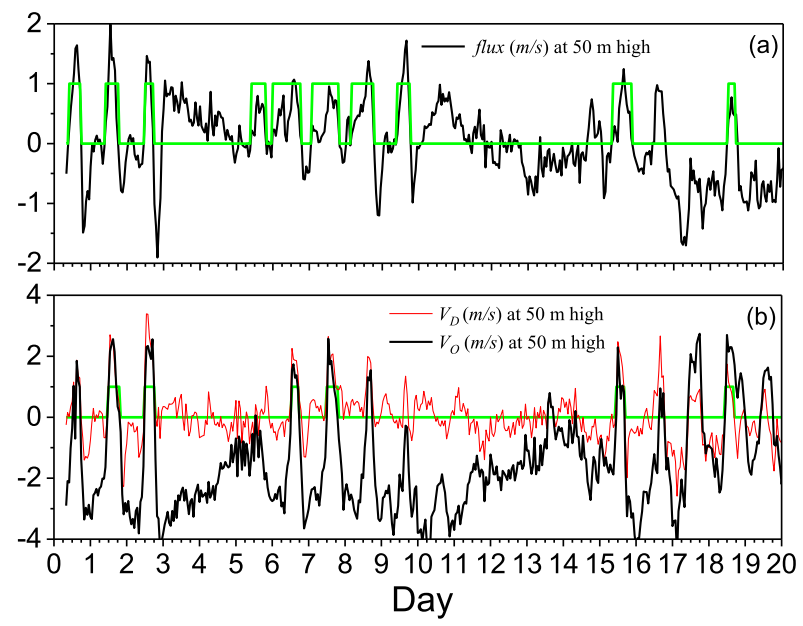

FIG. 2. Time evolution of (a) flux and (b) $V_{D}$ (red line) and $V_{O}$ (black line) at $50 \mathrm{~m}$ (all in $\left.\mathrm{m} \mathrm{s}^{-1}\right)$. Green lines with values of 1 indicate sea-breeze events. 

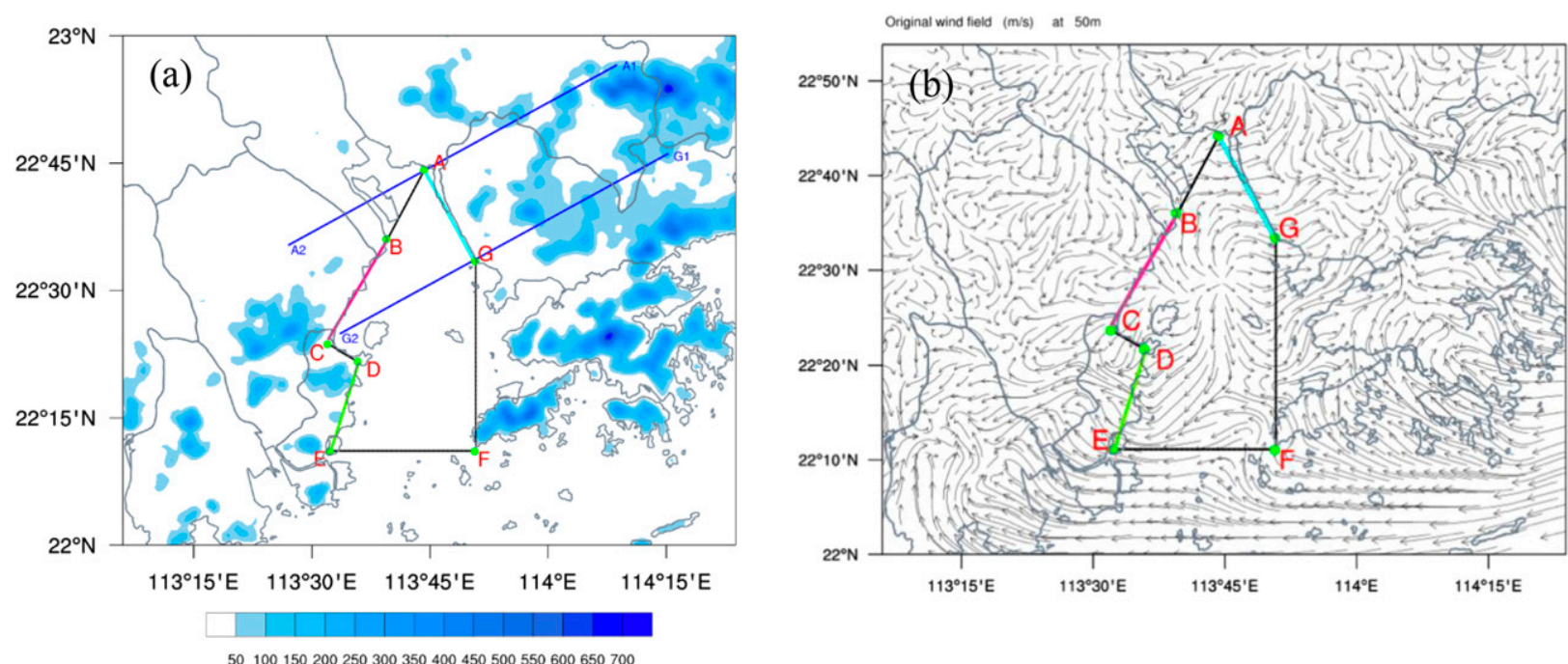

FIG. 3. (a) Terrain and coastlines in the PRD region. The PRD estuary is mostly enclosed by polygon ABCDEFG. Lines $\mathrm{A}_{1} \mathrm{~A}_{2}$ and $\mathrm{G}_{1} \mathrm{G}_{2}$ are perpendicular to coast $A G$ and intersect with it at points $A$ and $G$, respectively. (b) An example of a divergent center in the PRD estuary.

them, there is always one well-organized vortex over the coast, which is the central part of the sea-breeze circulation, which makes it possible to quantify $H_{\mathrm{SB}}$ clearly.

In the averaged vertical wind field (Fig. 4), the integrated $V$ over height, that is, $f_{x}$, is also evaluated. It can be taken as the streamfunction in the two-dimensional nondivergent wind field, and the locations at which $f_{x}$ equals 0 can indicate the boundaries of the atmospheric circulation. Apparently, this is not applicable to the averaged wind cross section here, but it can still help to estimate the approximate boundary of the sea-breeze circulation in this study. In addition, $f_{x}$ at the height of $H_{\mathrm{SB}}$ over the coast $f_{H}$ can also quantify the pumping ability of the sea-breeze circulation. Its physical meaning is the averaged air volume pumped from the sea to land every second by the sea-breeze circulation.

\section{d. Inland-penetration distance of sea breezes}

As noted above, $f_{x}$ with a value of 0 can indicate the approximate boundary of the sea-breeze circulation, so the inland lateral boundary illustrated by $f_{x}$ can also help to estimate the inland-penetration distance of the sea breeze $D_{\mathrm{SB}}$. However, this method is not applicable to sea-breeze cases entirely concealed by background wind. For these cases, the sea-breeze circulation can hardly be identified in the averaged vertical wind cross section defined in section $2 b$. In other words, no inverse flow can be detected above the sea breeze. Therefore, when this method is used, these cases can be excluded with the requirement that inverse flow should be found within $2000 \mathrm{~m}$ from the ground. The height of $2000 \mathrm{~m}$ is chosen here because most sea breezes are within this height. We are more interested in sea breezes with a strong and straight head front; therefore, the difference between $D_{\mathrm{SB}}$ at $50 \mathrm{~m}$ and $D_{\mathrm{SB}}$ at $H_{\mathrm{SB}}$ should be within $2000 \mathrm{~m}$.

\section{Sea breezes in the PRD region}

The method identified in section 2 is used to characterize estuary sea-breeze circulations in the PRD region hour by hour during 2012. Some basic statistical results

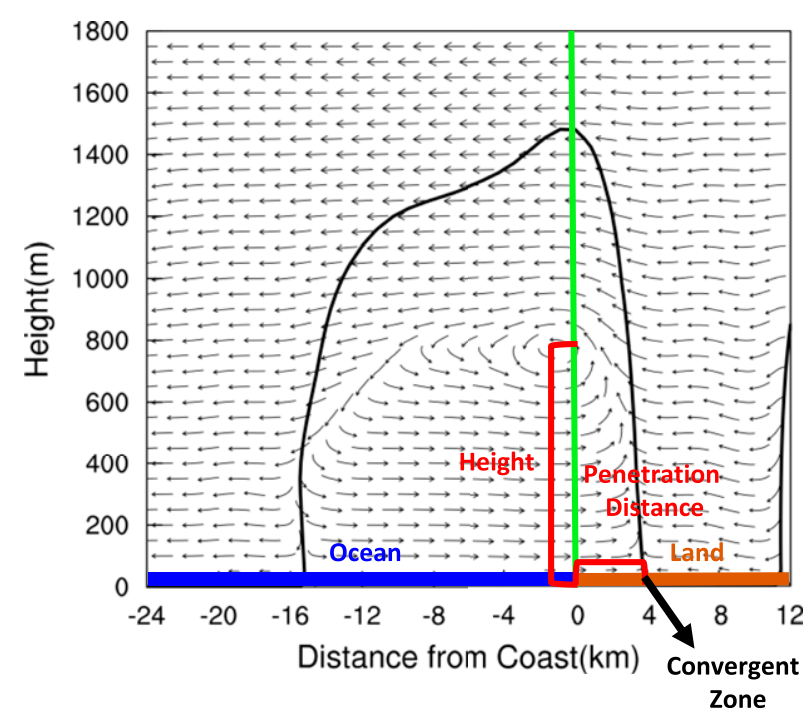

FIG. 4. Mean sea-breeze circulation averaged from line $\mathrm{A}_{1} \mathrm{~A}_{2}$ to line $G_{1} G_{2}$. The thick black line indicates a streamfunction with a value of 0 , which can approximate the boundary of the sea-breeze circulation. 

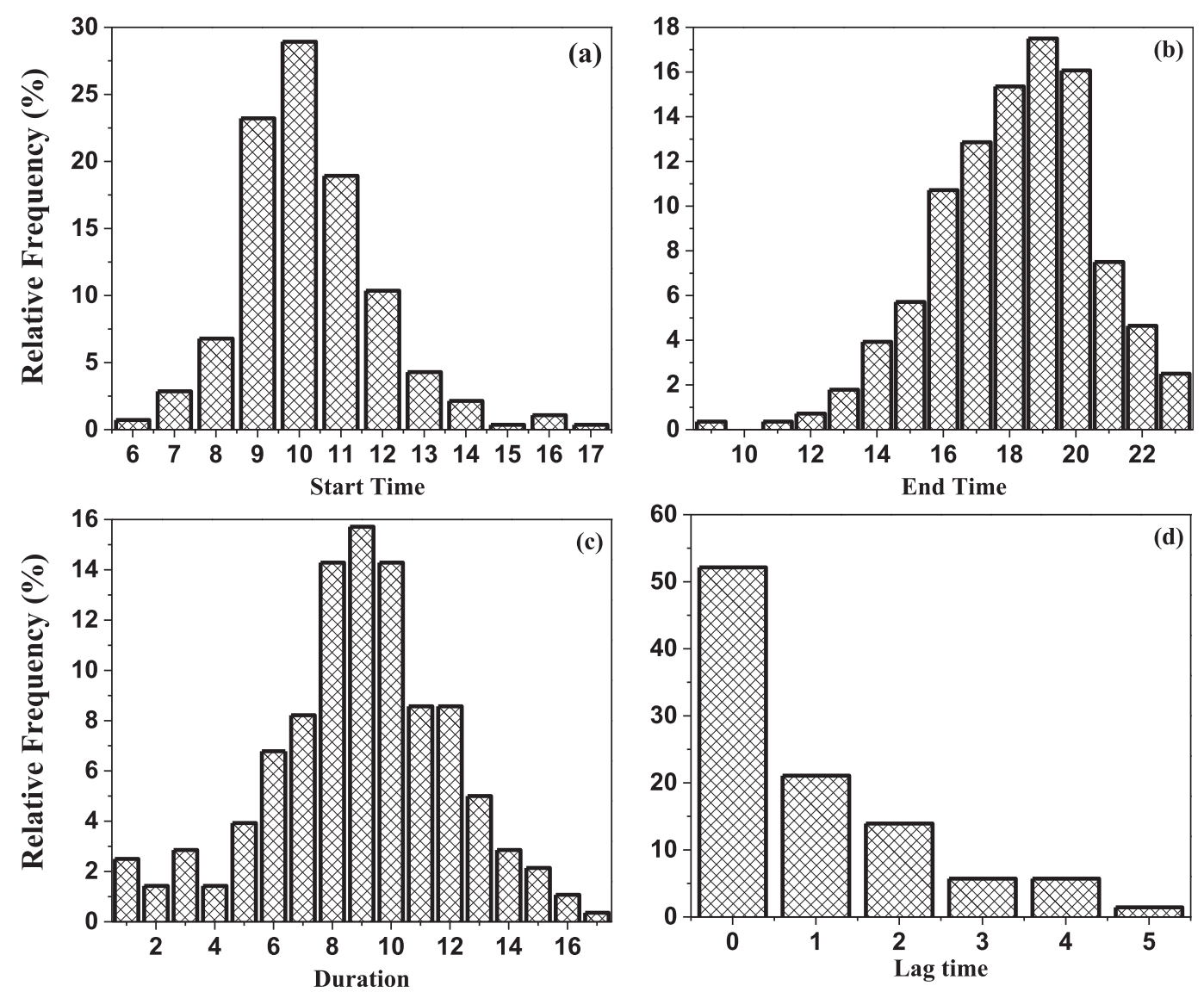

FIG. 5. Frequency count of (a) start time, (b) end time, (c) duration, and (d) lag time of sea-breeze events.

are summarized in Table 1 and Fig. 5. The sea-breeze events appear most frequently at coast $\mathrm{AG}$ and least frequently at coast $\mathrm{BC}$ (Table 2 ). The yearly averaged intensity is also the strongest at coast $\mathrm{AG}$ but the weakest at coast $\mathrm{BC}$.

The sea-breeze events at coasts $\mathrm{BC}$ and $\mathrm{DE}$ appear to begin earlier than those at coast AG, but the end times of the sea-breeze events at these three coasts are all

TABLE 2. Number of sea-breeze events, yearly averaged intensity, maximum intensity, background wind $V_{B}$, start time, end time, background wind, and linear correlation coefficient between intensity and background wind in 2012. The linear correlation coefficients are all significant at the 0.05 level.

\begin{tabular}{lccc}
\hline & Coast AG & Coast BC & Coast DE \\
\hline No. of sea-breeze events (days) & 114 & 70 & 96 \\
Intensity $\left(\mathrm{m} \mathrm{s}^{-1}\right)$ & 1.37 & 1.10 & 1.35 \\
Maximum intensity $\left(\mathrm{m} \mathrm{s}^{-1}\right)$ & 2.24 & 1.90 & 2.21 \\
Start time (LT) & 1030 & 1009 & 0959 \\
End time (LT) & 1811 & 1815 & 1806 \\
Background wind $\left(\mathrm{m} \mathrm{s}^{-1}\right)$ & -0.04 & 1.10 & 0.76 \\
Correlation coefficient between & -0.77 & -0.34 & -0.65 \\
$\quad$ intensity and $V_{B}$ & & & \\
\hline
\end{tabular}

around 1810 LT. Typically, the start time of most seabreeze events in the PRD region is 0900-1100 LT (Fig. 5a), and the end time is $1600-1800$ LT (Fig. 5b). Most sea-breeze events last around 6-12 h (Fig. 5c). Almost half of sea-breeze events terminate at or before sunset, and all sea-breeze events finish within $5 \mathrm{~h}$ after sunset (Fig. 5d).

\section{a. Monthly averaged intensity, background wind, and monthly frequency}

The yearly variations in the monthly averaged intensity and frequency differ greatly among these three coasts [Figs. $6 a(1), b(1), c(1)]$. At coast AG, the monthly frequency of sea-breeze events is comparatively low in February (1 case) and December (4 cases), whereas the frequency varies around 10 in other months and reaches its maximum in October [15 cases; Fig. 6a(1)]. For coasts DE and BC [Figs. 6b(1),c(1)], sea-breeze events occur most frequently in July but less frequently in January (three cases for both coasts), February (two cases for both coasts), and December (four cases at coast DE and three cases at coast BC). For coast DE [Fig. 6b(1)], the frequency is also low in November (four cases). 

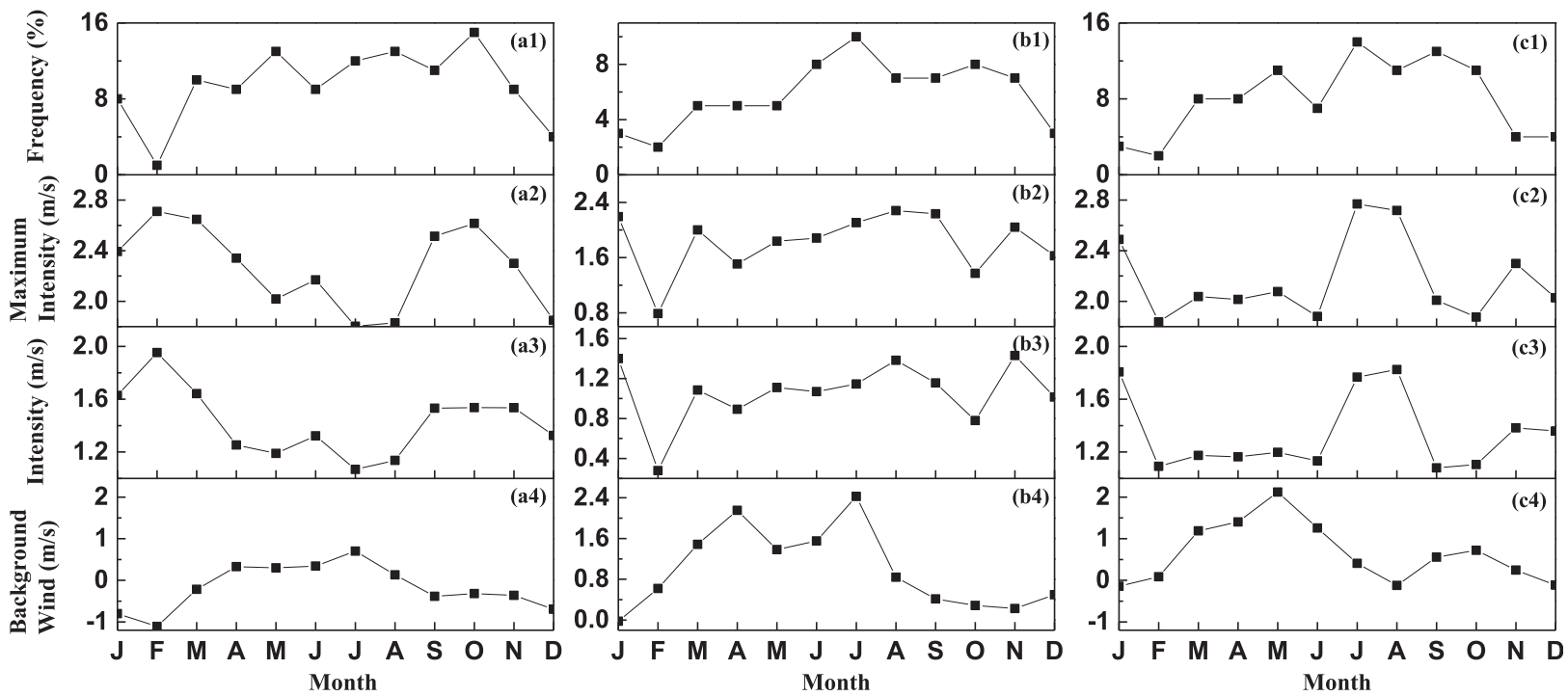

FIG. 6. Yearly variation of $[\mathrm{a}(1)]$ frequency (days), [a(2)] maximum intensity $\left(\mathrm{m} \mathrm{s}^{-1}\right),[\mathrm{a}(3)]$ intensity $\left(\mathrm{m} \mathrm{s}^{-1}\right)$, and [a(4)] background wind $\left(\mathrm{m} \mathrm{s}^{-1}\right)$ by month at coast AG in 2012. [b(1)]-[b(4)], [c(1)]-[c(4)] As in [a(1)]-[a(4)], but for coasts BC and DE.

The yearly variation tendencies of the monthly averaged intensity differed greatly among the three coasts [Figs. 6a(3),b(3),c(3)]. At coast AG [Fig. 6a(3)], the sea breeze is relatively stronger from January to March and from September to November but comparatively weaker in July and August. However, for coast DE [Fig. 6b(3)], the sea breeze is apparently stronger in July, August, and January. At coast BC [Fig. 6c(3)], with the exception of February, the monthly averaged intensity of the sea breeze fluctuates around $1.2 \mathrm{~m} \mathrm{~s}^{-1}$ and varies little from month to month. The yearly variation of monthly averaged maximum intensity [Figs. $6 a(2), b(2)$, $c(2)]$ is similar to that of the monthly averaged intensity.

As mentioned in section $2 \mathrm{c}$, background wind $V_{B}$ in this study is defined as nondivergent velocity perpendicular to each coast. A positive $V_{B}$ means that its direction is same as that of the sea breeze (onshore), whereas a negative $V_{B}$ implies that its direction is opposite that of the sea breeze (offshore). The yearly averaged $V_{B}$ during sea-breeze events at coast $\mathrm{AG}$ is offshore, but it is onshore for coasts $\mathrm{BC}$ and $\mathrm{DE}$ (Table 2). This asymmetrical distribution of background wind is consistent with the finding of $\mathrm{Lu}$ et al. (2009). Arritt (1993) found that a sea breeze may be generally suppressed by the onshore background wind but strengthened by the offshore background wind because of the weaker or enhanced convergence zone in the coastal region. According to this finding, the sea breeze at coast AG is enhanced by the offshore background wind, but the sea breezes at coasts $\mathrm{BC}$ and $\mathrm{DE}$ are suppressed by the onshore background wind, which can explain why the sea breeze at coast AG is stronger than those at the other two coasts. A negative correlation is apparent between the monthly averaged $V_{B}$ and the monthly averaged sea-breeze intensity at coasts $A G$ and DE [Figs. $6 a(3), 6 b(3),(4)$ ], but the negative correlation at coast $\mathrm{BC}$ is less obvious than those of the other two coasts (Table 2), possibly because of the relatively smaller estuaries (Hengmen, Hongqili, and Jiaomen waterways) near coast $\mathrm{BC}$. The averaged $V_{B}$ and averaged intensity are evaluated for each sea-breeze event, and the linear correlation coefficient between these two variables is -0.77 at coast $A G,-0.65$ at coast $D E$, and -0.34 at coast $\mathrm{BC}$ (Table 2 ).

\section{b. Characteristics of separable sea-breeze events}

Some characteristics of sea-breeze events, such as the inland-penetration distance, height, and pumping ability, can only be quantified among separable events identified with the method in section 2 . These characteristics are summarized for each coast in Table 3. Coast AG has many more separable sea-breeze events than the other two coasts, probably because the offshore $V_{B}$ is much stronger and more frequent. However, in general, sea-breeze events along coast $\mathrm{BC}$ can penetrate farther

TABLE 3. Number of separable cases, yearly averaged inlandpenetration distance $D_{\mathrm{SB}}$, height $H_{\mathrm{SB}}$, and pumping ability $f_{H}$.

\begin{tabular}{lccc}
\hline \hline & Coast AG & Coast BC & Coast DE \\
\hline No. of separable cases (days) & 103 & 41 & 52 \\
$D_{\mathrm{SB}}(\mathrm{km})$ & 17 & 30 & 26 \\
$H_{\mathrm{SB}}(\mathrm{m})$ & 707 & 729 & 706 \\
$f_{H}\left(\mathrm{~m}^{3} \mathrm{~s}^{-1}\right)$ & 1028 & 1150 & 1065 \\
\hline
\end{tabular}



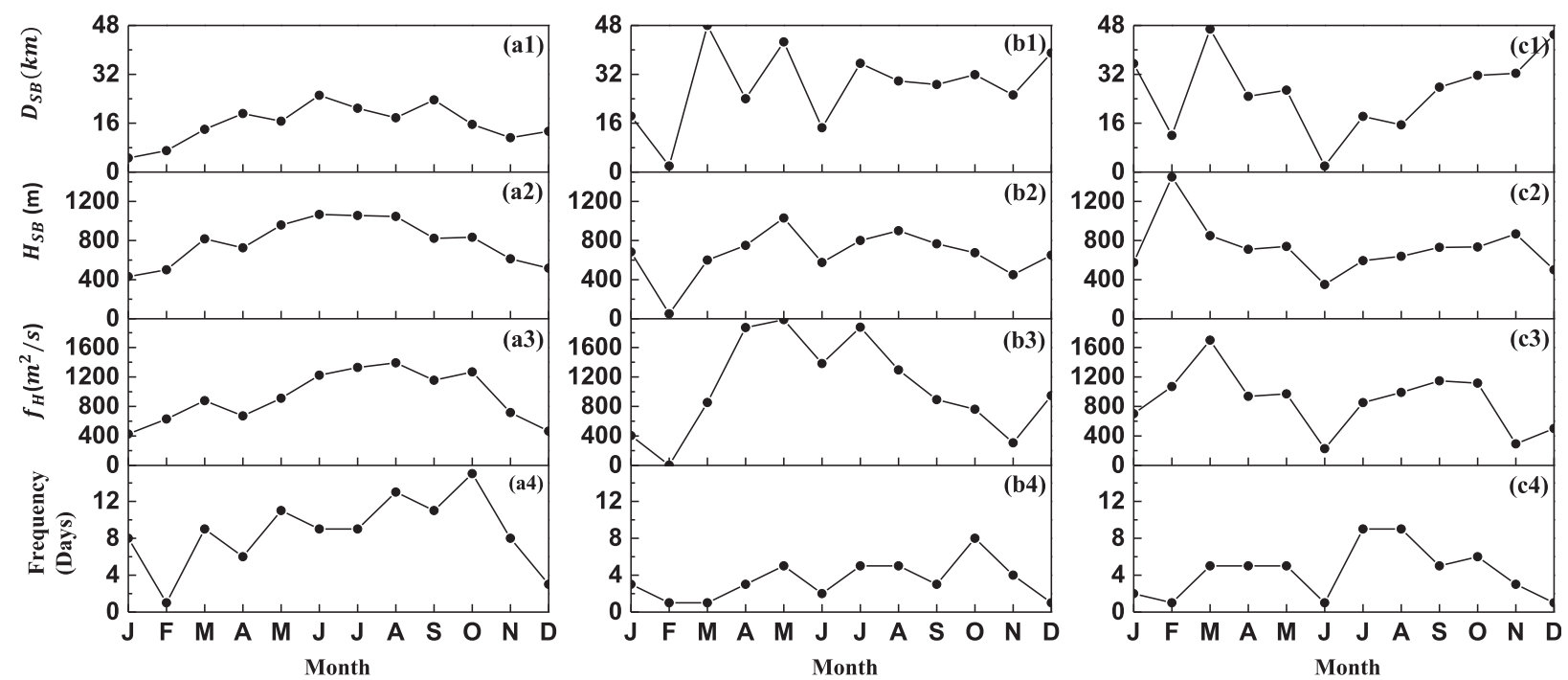

FIG. 7. Yearly variation of monthly averaged $[\mathrm{a}(1)] D_{\mathrm{SB}}(\mathrm{km}),[\mathrm{a}(2)] H_{\mathrm{SB}}(\mathrm{m}),[\mathrm{a}(3)] f_{H}\left(\mathrm{~m}^{2} \mathrm{~s}^{-1}\right)$, and $[\mathrm{a}(4)]$ monthly frequency $($ days $)$ at coast AG in 2012. [b(1)]-[b(4)], [c(1)]-[c(4)] As in [a(1)]-[a(4)], but for coasts BC and DE.

inland, and its height and pumping ability are also the greatest among these three coasts. On average, the sea breeze along coast DE can penetrate farther inland than that of coast AG, but their height and pumping ability are similar.

Generally, along these three coasts, the yearly variation tendency of $D_{\mathrm{SB}}$ and $H_{\mathrm{SB}}$ are similar to that of $f_{H}$ (Fig. 7). For coast AG [Figs. 7a(1)-(4)], $D_{\mathrm{SB}}$ and $H_{\mathrm{SB}}$ increase from January to June almost monotonically (if April is not considered), and these two variables reach their maximums in June. The $D_{\mathrm{SB}}$ and $H_{\mathrm{SB}}$ then decrease monotonically from June to December (except for September). The yearly variation in $f_{H}$ is roughly parallel to that of $H_{\mathrm{SB}}$ except that the maximum value of $f_{H}$ is in August. For coasts BC and DE [Figs. 6b(1)-(4) and 6c(1)-(4)], the variation tendencies of $D_{\mathrm{SB}}, H_{\mathrm{SB}}$, and $f_{H}$ from January to June are almost symmetric with those from June to December. Each of these three variables along coasts $\mathrm{BC}$ and $\mathrm{DE}$ reach their local minimum values in June [for coast DE, it is also the global minimum value; see Figs. 6b(1)-(4) and 6c(1)-(4)]. For coast DE [Figs. $7 \mathrm{c}(1)-(4)], D_{\mathrm{SB}}, H_{\mathrm{SB}}$, and $f_{H}$ are apparently smaller from May to July than in other months. However, at coast BC [Figs. 7b(1)-(4)], these three values are larger in May and July than in most other months.

\section{c. Vertical structure of the sea-breeze circulation}

For all separable sea-breeze events at coast $\mathrm{AG}$, the vertical profile of $f_{x}$ and $V_{O}$ over the coast (Fig. 8) and $W$ (vertical velocity) and potential temperature $T_{p}$ (Fig. 9)
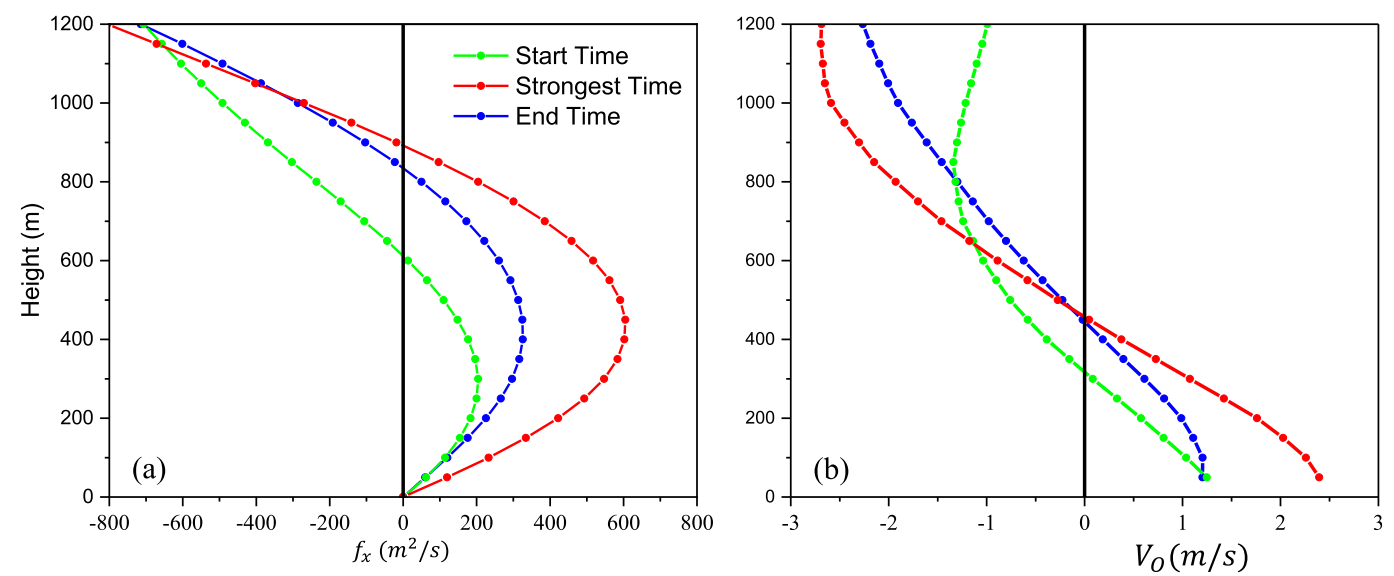

FIG. 8. Averaged vertical profile of (a) $f_{x}$ and (b) $V_{O}$ over coast AG at the start time (green), strongest time (red), and end time (blue). Maximum value of $f_{x}$ is $f_{H}$. 

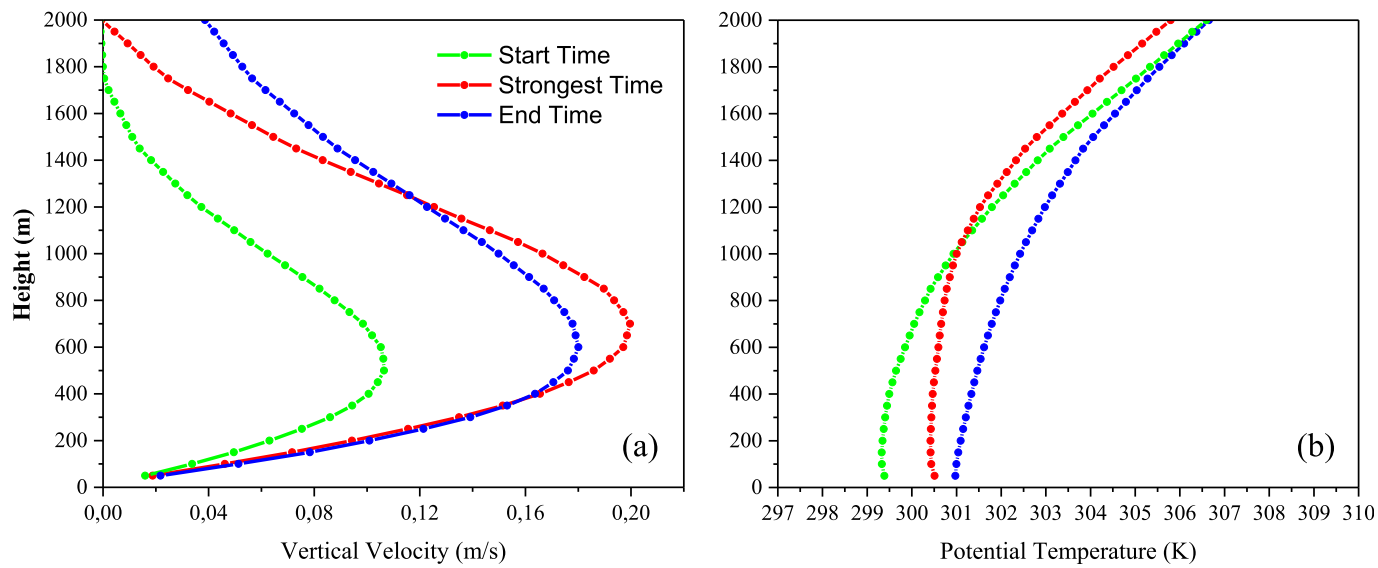

FIG. 9. Averaged vertical profile of (a) vertical velocity $W$ and (b) $\theta$ over the convergent zone near coast AG at the start time (green), strongest time (red), and end time (blue).

above the convergent zone are averaged at the moments when the sea-breeze events begin, terminate, and reach their maximum intensity, respectively. Figures 8 and 9 illustrate the averaged developing process of sea-breeze events along coast AG. From the start time to the strongest time, $f_{H}, V_{O}$, and the maximum $W$ are all enhanced. Meanwhile, the height of the sea breeze and the sea-breeze circulation increase from 300 to $450 \mathrm{~m}$ (Fig. 8b) and from 600 to $850 \mathrm{~m}$ (Fig. 8a), respectively. The height of the maximum $W$ also shifts from 500 to $750 \mathrm{~m}$ (Fig. 9a). From the strongest time to the end time, $f_{H}, V_{O}$, and the maximum $W$ are reduced but are still stronger than those at the start time. At the same time, the height of the sea breeze, the sea-breeze circulation, and the maximum $W$ are also decreased slightly from 450 to $400 \mathrm{~m}$, from 850 to $800 \mathrm{~m}$, and from 750 to $600 \mathrm{~m}$, respectively. At these three moments, the height of the maximum $W$ over the convergent zone is greater than that of the sea breeze but lower than that of the seabreeze circulation. In addition, the sea breeze decreases monotonically with height. Because of the greater vertical velocity at the convergent zone, the atmospheric boundary layer (Fig. 9b) is much better mixed than that over the coast. This result indicates that atmospheric stability can be reduced by the increased vertical velocity along the sea-breeze front. At both the beginning and the strongest time of the sea breeze, a shallow unstable layer could be found near the surface, but it disappears by the end time. With stronger vertical motion at the strongest time, the boundary layer at this moment is perfectly mixed among these three moments. Meanwhile, the height of the lifted inversion layer appears to be increased from that at the start time. At the end time, the boundary layer becomes much more stable, and the well-mixed layer vanishes. Similar results can also be achieved along the other two coasts. In contrast, at the end time, the heights of the sea breeze and the sea-breeze circulation at coast BC are almost parallel to and even slightly higher than that seen at the strongest time.

\section{Dynamical diagnosis of sea-breeze circulation}

In this section, the vorticity equation is used to diagnose dynamic factors that contribute to the development of the sea-breeze circulation. The vorticity $\zeta$ is evaluated by Eq. (1) in the Cartesian coordinate system where the $y$ axis is parallel to the coast (Fig. 10):

$$
\zeta=\nabla \times \mathbf{V}=\frac{\partial w}{\partial x}-\frac{\partial V}{\partial z} .
$$

In Eq. (1), $\mathbf{V}$ is the wind vector parallel to the $x-z$ plane, $V(w)$ is its horizontal (vertical) component, and the gradient operator $\nabla$ here is defined as $(\partial / \partial x, \partial / \partial z)$. Vorticity acceleration (VA) is evaluated by

$$
\begin{aligned}
\frac{d \zeta}{d t}= & -\nabla \alpha \times \nabla p+\left(\tilde{f} \frac{\partial u}{\partial x}+f \frac{\partial u}{\partial z} \sin \vartheta+f \frac{\partial v}{\partial z} \cos \vartheta-\tilde{f} \frac{\partial w}{\partial z} \cos \vartheta\right)+\left(\frac{\partial F_{z}}{\partial x}-\frac{\partial F_{x}}{\partial z}\right) \\
& -(\nabla \cdot \mathbf{V}) \zeta+(\boldsymbol{\omega} \cdot \nabla)(u \sin \vartheta+v \cos \vartheta)=\mathrm{VA} 1+\mathrm{VA} 2+\mathrm{VA} 3+\mathrm{VA} 4+\mathrm{VA} 5, \quad \text { where } \\
f= & 2 \Omega \sin \varphi, \quad \tilde{f}=2 \Omega \cos \varphi .
\end{aligned}
$$




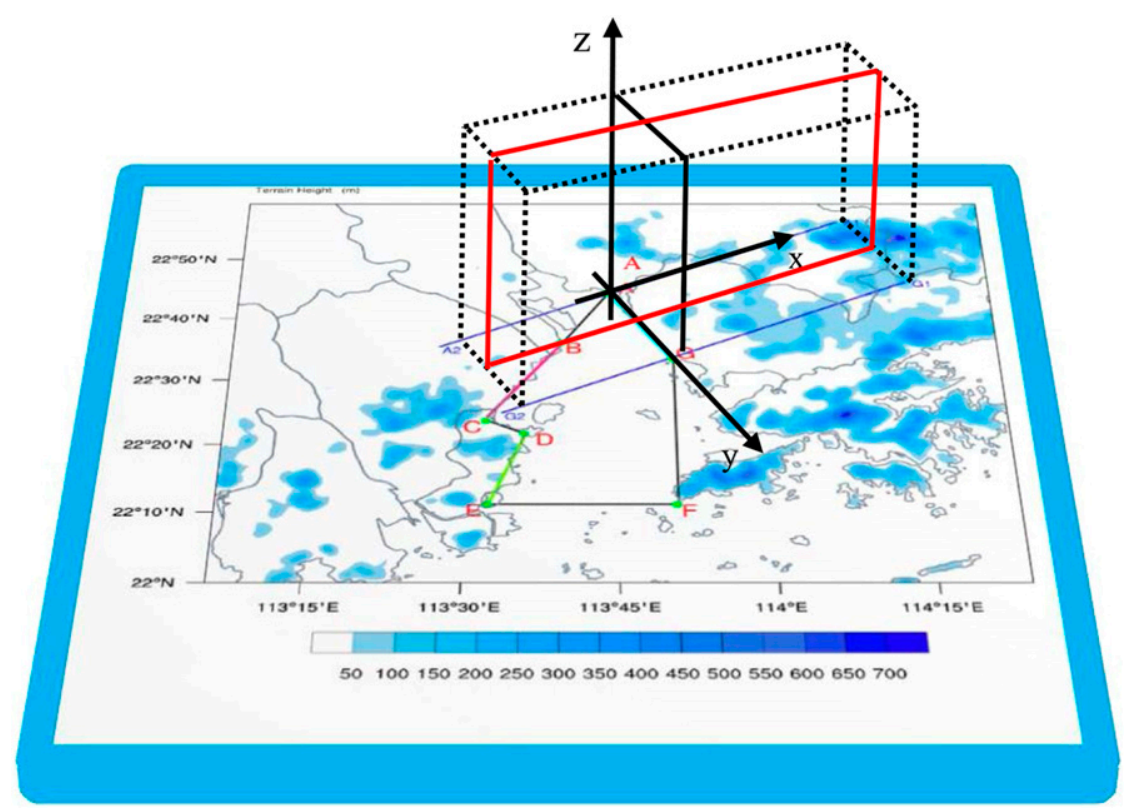

FIG. 10. The terms in most of the equations used here are evaluated in the Cartesian coordinate system shown, where the $y$ axis coincides with coast AG and the $x$ axis overlaps line $A_{1} A_{2}$. We mainly focus on variables on the mean vertical cross section (the red rectangle), which is achieved by averaging the three-dimensional physical variables in the black box over the $y$ direction.

In Eq. (2), $\boldsymbol{\omega}$ is the three-dimensional vorticity, $u(v)$ is the latitudinal (meridional) velocity component, $\vartheta$ is the angle between the coastline and the north-south cross section, $F_{x}\left(F_{z}\right)$ is the horizontal (vertical) component of atmospheric viscous force, $\varphi$ is latitude, and $\Omega$ is the angular velocity of Earth. In addition, VA1, VA2, VA3, VA4, and VA5 represent the effects from the solenoid term, the Coriolis force, atmospheric viscosity, divergence, and tilting, respectively.

All of these terms are evaluated on the vertical cross sections perpendicular to the coast with intervals of $1 \mathrm{~km}$ and averaged in the $y$ direction at the start time, strongest time, and end time of the sea breeze for the whole of 2012. According to our calculation, VA2, VA4, and VA5 are relatively too small to consider, so VA is mainly controlled by positive VA1 and negative VA3. That is to say, the seabreeze circulation is fueled by the solenoid term, whereas VA3 is used to offset the positive effects of the solenoid term. The magnitude and spatial distribution of VA1 + VA3 are almost same as that of VA (Fig. 11).

\section{a. Solenoid term during the development of sea-breeze circulation}

The solenoid term $-\nabla \alpha \times \nabla p$ is the largest positive contributor to the vorticity acceleration among the five terms on the right side of Eq. (2). It can also be written as

$$
\begin{aligned}
-\nabla \alpha \times \nabla p & =|\alpha \nabla p|\left|\nabla_{p} \ln \theta_{v}\right| \frac{\sin \vartheta_{1}}{\left|\sin \vartheta_{1}\right|}\left|\nabla_{p} \ln \theta_{v}\right| \\
& =\left|\nabla_{p} \ln T_{v}\right|=\left|\nabla \ln \frac{R_{d} T_{v}}{p} \cdot \sin \vartheta_{1}\right|, \\
\vartheta_{1} & =\cos ^{-1} \frac{\nabla p \cdot \nabla \alpha}{|\nabla p||\nabla \alpha|},
\end{aligned}
$$

where $\nabla_{p}$ is a horizontal gradient operator on an isobaric surface and $\nabla$ is a horizontal gradient operator on a constant height surface. In light of Eq. (3), the solenoid term is composed of two components, the pressure gradient force $|\alpha \nabla p|$ and the virtual temperature gradient $\left|\nabla_{p} \ln \theta_{v}\right|$.

The time evolution of these physical variables including the pressure field, potential temperature, the solenoid term, and the temperature gradient are shown in Fig. 12. From the start time of a sea-breeze event to its end time, the pressure field does not change very much, and in all three moments, the pressure above the sea is slightly larger than that on the land (Figs. 12a-c). The spatial distribution and time evolution of temperature gradient are almost the same as the solenoid term (Figs. $12 \mathrm{~d}-\mathrm{f}, \mathrm{g}-\mathrm{i}$ ), while the pressure gradient force is nearly constant (Fig. 13). In other words, the solenoid term is mostly controlled by the virtual temperature gradient. The maximum value of the solenoid term is always located over the coast. From the start time to the strongest time, the solenoid term develops strikingly 
(a)VA at Start Time

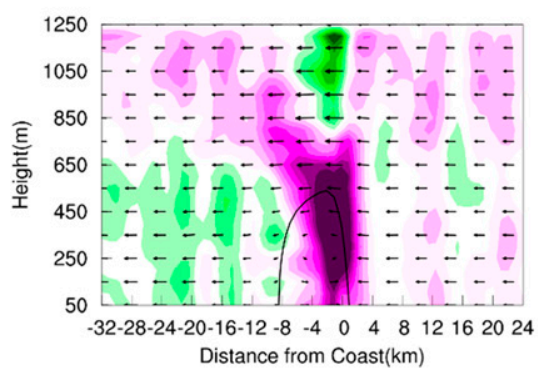

(d)VA3+VA1 at Start Time

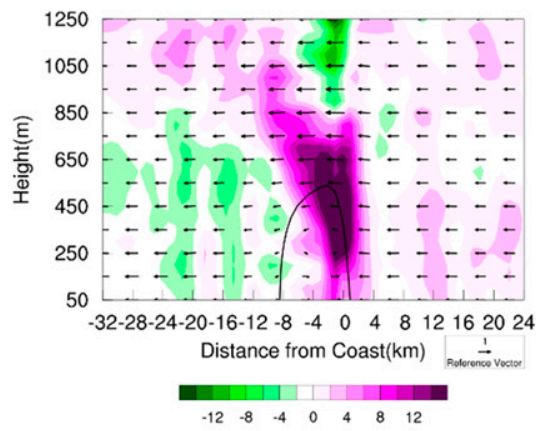

(b)VA at Strongest Time

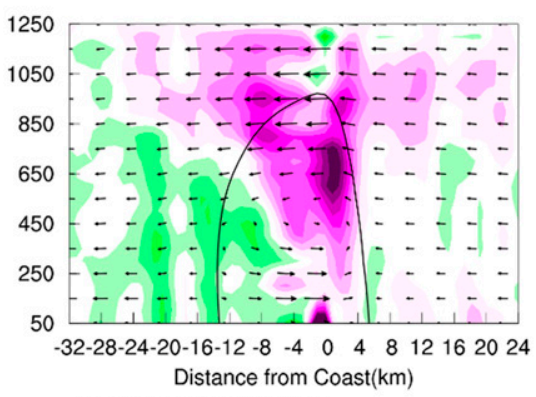

(e)VA3+VA1 at Strongest Time

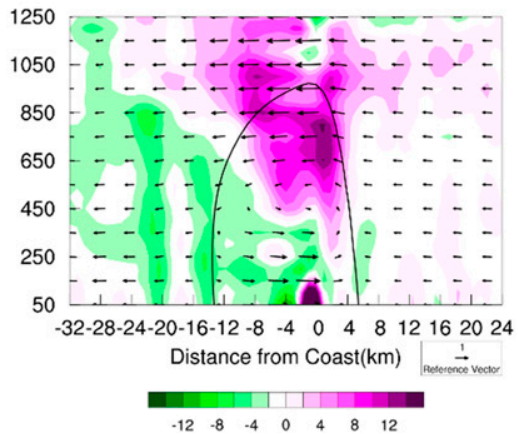

(c)VA at End Time
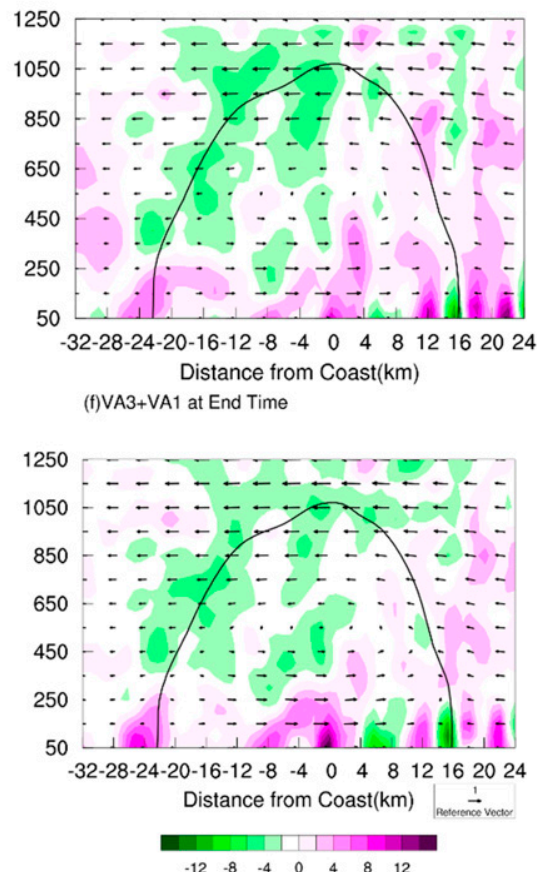

FIG. 11. Yearly averaged VA (shaded contours; $10^{-7} \mathrm{~s}^{-2}$ ) and original wind fields $\left(\mathrm{m} \mathrm{s}^{-1}\right)$ of sea-breeze circulations along coast AG, at its (a) start time, (b) strongest time, and (c) end time. The thick black line indicates a streamfunction with a value of 0 , which can approximately indicate the boundary of the sea-breeze circulation. (d)-(f) As in (a)-(c), but for VA3 + VA1.

and extends both vertically and horizontally (Figs. 12d,e). Meanwhile, the sea-breeze circulation also develops to a higher level and penetrates farther both onshore and offshore. However, at the end time, the positive solenoid term has largely diminished and nearly disappeared (Fig. 12f). At that moment, the scale of the sea-breeze circulation, including its height, inlandpenetration distance, and offshore penetration distance, reaches its maximum. Afterward, the sea-breeze circulation shrinks promptly without the driving force of the solenoid term.

\section{b. Sea-breeze frontogenesis}

Since the solenoid term, the largest positive contributor to vorticity acceleration, is mainly controlled by the temperature gradient, the frontogenesis function is utilized in this study to diagnose factors that may affect the temperature gradient and therefore modulate the development of sea-breeze circulation. Kraus et al. (1990) and Finkele et al. (1995) did observational aircraft-based studies about sea-breeze frontogenesis. However, it is assumed that the structure of the sea-breeze circulation is frozen during the observation, and they were also not able to capture the continuous process of sea-breeze development. In this section, the yearly averaged frontogenesis function will be evaluated at the start, strongest, and end time of the sea breeze. According to the frontogenesis function (Ninomiya 1984),

$$
\frac{d}{d t}\left|\nabla_{p} \ln T_{v}\right|=\frac{d}{d t}\left|\nabla_{p} \ln \theta_{v}\right|=\mathrm{FG} 1+\mathrm{FG} 2+\mathrm{FG} 3+\mathrm{FG} 4,
$$

where the four forcing terms on the right-hand side, respectively, are

$$
\begin{aligned}
\mathrm{FG} 1= & \frac{1}{\left|\nabla_{p} \ln \theta_{v}\right|}\left[\nabla_{p} \ln \theta_{v} \cdot \nabla_{p}\left(\frac{d}{d t} \ln \theta_{v}\right)\right], \\
\mathrm{FG} 2= & -\frac{1}{2\left|\nabla_{p} \ln \theta_{v}\right|}\left[\left(\frac{\partial}{\partial x} \ln \theta_{v}\right)^{2}\right. \\
& \left.+\left(\frac{\partial}{\partial y} \ln \theta_{v}\right)^{2}\right]\left(\frac{\partial u}{\partial x}+\frac{\partial v}{\partial y}\right), \\
\mathrm{FG} 3= & -\frac{1}{\left|\nabla_{p} \ln \theta_{v}\right|}\left\{\frac { 1 } { 2 } \left[\left(\frac{\partial}{\partial x} \ln \theta_{v}\right)^{2}\right.\right. \\
& \left.-\left(\frac{\partial}{\partial y} \ln \theta_{v}\right)^{2}\right]\left(\frac{\partial u}{\partial x}-\frac{\partial v}{\partial y}\right) \\
& \left.+\frac{\partial \ln \theta_{v}}{\partial x} \frac{\partial \ln \theta_{v}}{\partial y}\left(\frac{\partial v}{\partial x}+\frac{\partial u}{\partial y}\right)\right\}, \quad \text { and }
\end{aligned}
$$



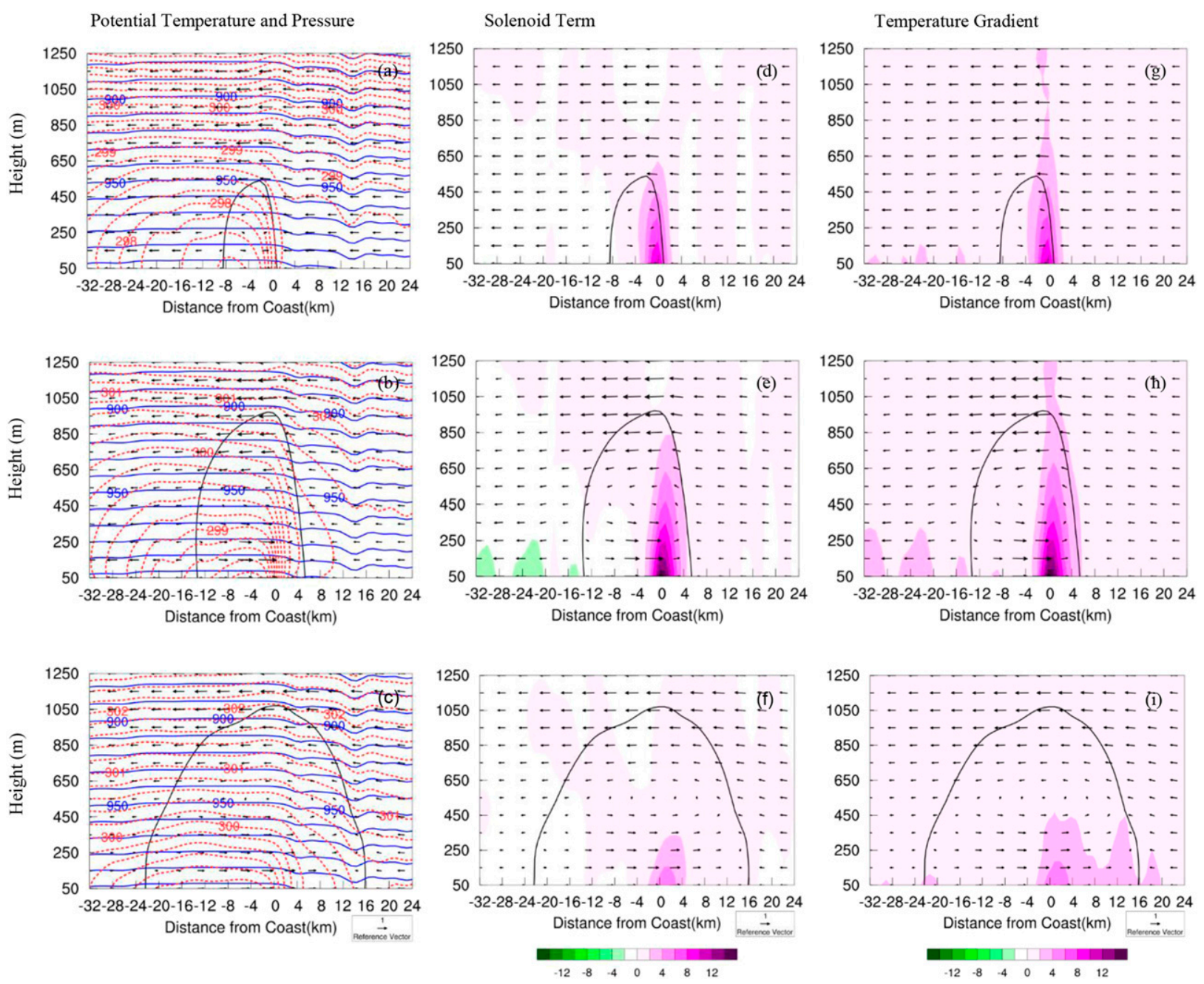

FIG. 12. (a)-(c) Yearly averaged pressure (blue solid line; hPa), potential temperature (red dashed line; K), and original wind field $\left(\mathrm{m} \mathrm{s}^{-1}\right)$ of sea-breeze circulations along coast AG, at its (a) start time, (b) strongest time, and (c) end time. The thick black line is a streamfunction with a value of 0 , which can approximately indicate the boundary of the sea-breeze circulation. (d)-(f) As in (a)-(c), but for the solenoid term (shaded contours; $10^{-6} \mathrm{~s}^{-2}$ ). (g)-(i) As in (a)-(c), but for the temperature gradient (shaded contours; $10^{-7} \mathrm{k} \mathrm{m}^{-1}$ ).

$$
\mathrm{FG} 4=-\frac{1}{\left|\nabla_{p} \ln \theta_{v}\right|}\left[\frac{\partial \ln \theta_{v}}{\partial p}\left(\nabla_{p} \ln \theta_{v} \cdot \nabla_{p} \omega\right)\right]
$$

where the temperature gradient is controlled by FG1, FG2, FG3, and FG4, which represent the effects of diabatic processes, horizontal convergence, deformation, and tilting, respectively.

Similarly, these four terms are evaluated for all seabreeze events of 2012 and averaged at the start time, strongest time, and end time. Positive FG1 means that the diabatic heating in the warmer region is stronger than it is in the cooler region, which could enhance the temperature gradient. At or even before the start time of the sea breeze, the air above the land is already warmer than that over the sea. Diabatic heating on the land is also stronger than that above the sea. Hence, strong FG1 can be found over the coastal region at the start time. At the strongest time, FG1 becomes much stronger (Fig. 14b), and with declining solar radiation, FG1 decreases dramatically at the end time.

The spatial distributions of FG4 at these three moments are similar to that of FG1, but their signs are opposite. FG4 quantifies the effects of vertical motion driven by the sea-breeze circulation on the temperature gradient. As is well known, for an adiabatic process, potential temperature remains constant. If the environmental atmosphere is stable $\left(\partial \ln \theta_{v} / \partial p<0\right)$, positive vertical motion pushes warmer air (i.e., that with higher potential temperature) upward, whereas negative vertical motion transports cooler air (i.e., that with lower potential temperature) downward. This process may diminish the horizontal temperature gradient (i.e., negative FG4). As shown in Figs. 12a-c, 

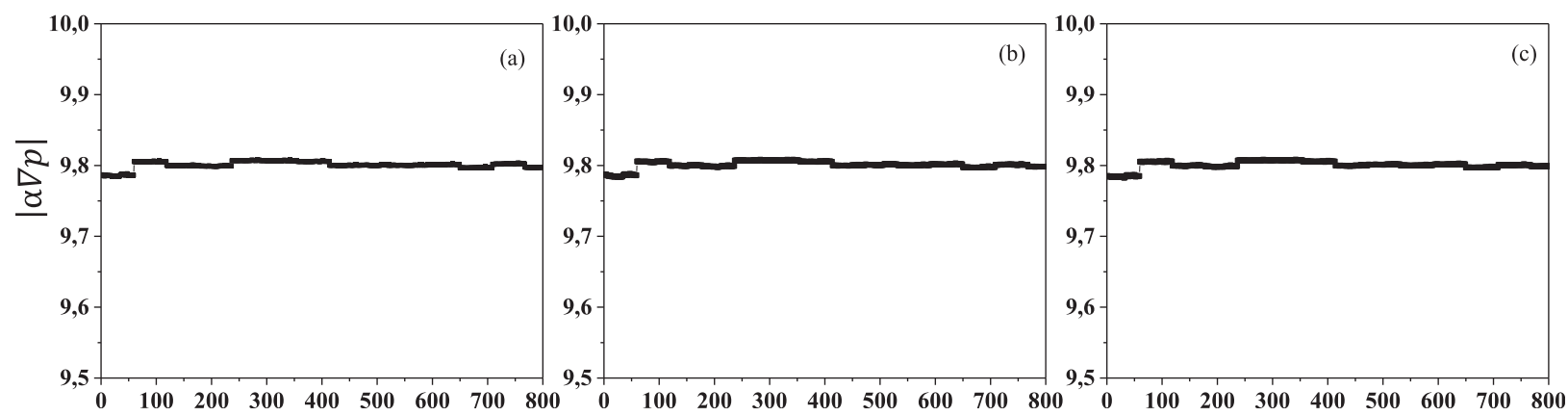

FIG. 13. Yearly averaged $|\alpha \nabla p|\left(\mathrm{m} \mathrm{s}^{-2}\right)$ on the averaged vertical cross section (the red rectangle shown in Fig. 10) at the (a) start time,

(b) strongest time, and (c) end time. It is plotted as a one-dimensional array of $1 \mathrm{~km}$ in height.

except for the well-mixed convergent zone where $\partial \ln \theta_{v} / \partial p$ nearly equals 0 , the environmental atmosphere is almost stable inside the area of sea-breeze circulation. Hence, minimum FG4 can be found between upward motion and downward motion (Fig. 14c). As the vertical motion is apparently enhanced at the strongest time, FG4 in this region decreases to a much smaller value. However, at the end time, with weakened vertical velocities
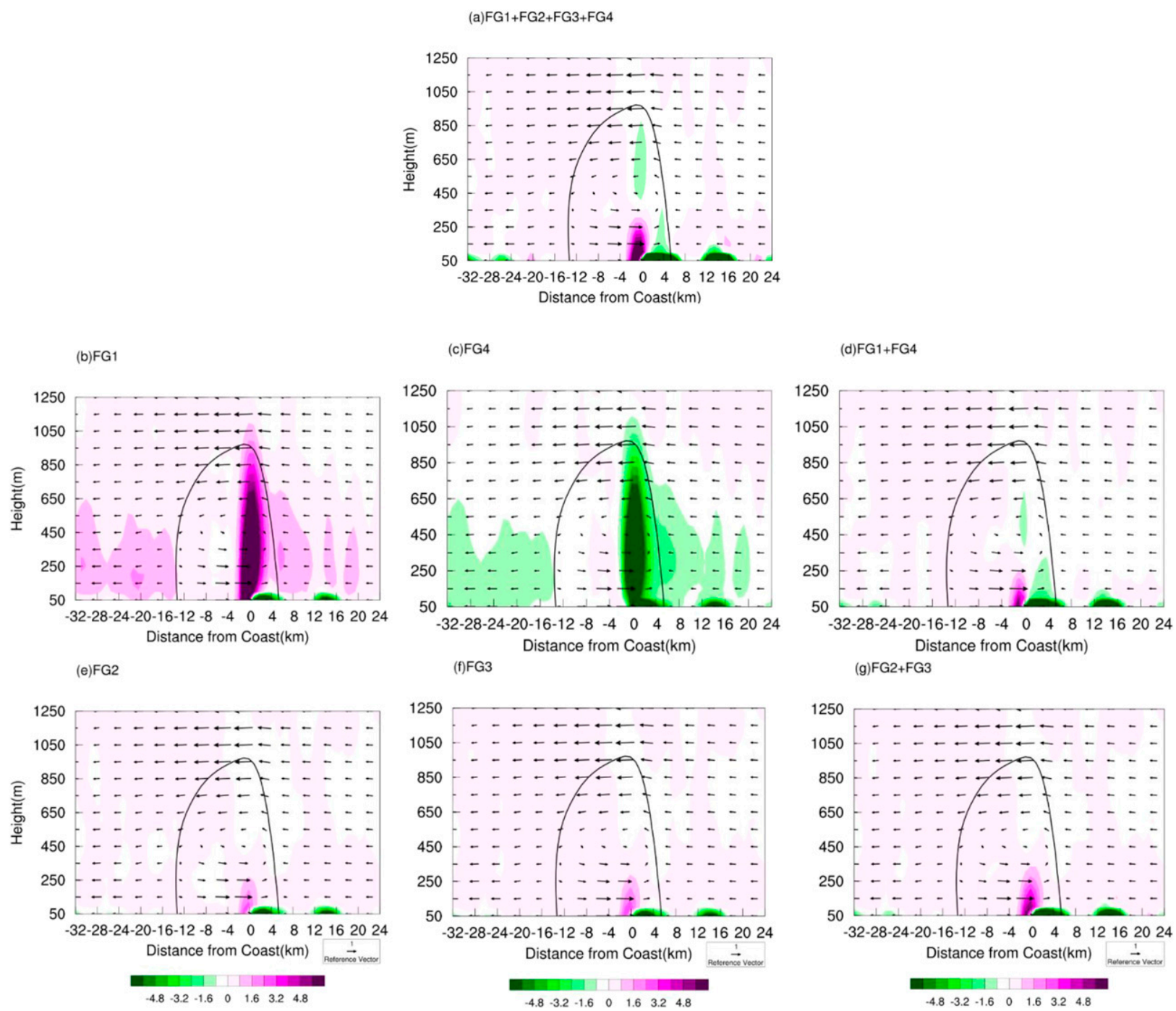

FIG. 14. Yearly averaged (a) FG1 + FG2 + FG3 + FG4, (b) FG1, (c) FG4, (d) FG1 + FG4, (e) FG2, (f) FG3, and (g) FG2 + FG3 all overlain with yearly averaged vertical wind fields along coast $A G$ at the strongest time of the sea breeze $\left(\right.$ units are $\left.10^{-11} \mathrm{~K} \mathrm{~m}^{-1} \mathrm{~s}^{-1}\right)$. 
TABLE 4. Number of cases of sea-breeze events developed in offshore and onshore background wind in 2012, the corresponding yearly averaged intensity and maximum intensity of the sea breeze, and yearly averaged offshore and onshore background wind.

\begin{tabular}{lcccr}
\hline \hline & No. of cases & Intensity $\left(\mathrm{m} \mathrm{s}^{-1}\right)$ & Maximum intensity $\left(\mathrm{m} \mathrm{s}^{-1}\right)$ & ${\text { Background wind }\left(\mathrm{m} \mathrm{s}^{-1}\right)}$ \\
\hline SB_off & 56 & 1.75 & 2.71 & -0.66 \\
SB_on & 47 & 1.07 & 1.90 & 0.45 \\
\hline
\end{tabular}

and further distance between upward and downward motion, the absolute value of FG4 is dramatically decreased. According to Fig. 14d, FG1 is almost offset by FG4, except in some marginal regions.

Divergence (FG2) and deformation (FG3) also have important impacts on the temperature gradient by densifying or thinning isotherms. At each moment, the distribution and magnitude of FG2 are almost parallel with that of FG3 (Figs. 14e,f). According to Eq. (7), deformation effects (FG3) are contributed by stretching deformation and rotational deformation, but their magnitudes and spatial distributions are almost the same. Generally, the overall effects from the wind field, FG2 + FG3, are obviously larger than the overall thermal effects, FG1 + FG4 (Figs. 14d,g).

The spatial distributions of $d / d t\left|\nabla_{p} \ln T_{v}\right|(\mathrm{FG} 1+$ FG2 + FG3 + FG4) (Fig. 14a) at each moment are similar to those of FG1 + FG4 (Fig. 14d) and FG2 + FG3
(Fig. 14g). This means that both FG1 + FG4 and FG2 + FG3 have similar impacts on $d / d t\left|\nabla_{p} \ln T_{v}\right|$ and convergence (divergence) in conjunction with positive (negative) deformation always exists together with heating (cooling).

Separable sea-breeze events at coast AG are divided into two groups: one developed in the offshore background wind, marked as SB_off, and the other in the onshore background wind, marked as SB_on. From Table 4, the yearly averaged intensity of SB_off is much stronger than SB_on, while its scale and propagation inland is obviously smaller than that of SB_on (Fig. 15). Arritt (1993) proposed that the offshore background wind enhances the convergence in the vicinity of the seabreeze front and therefore strengthens the frontogenesis there, as is verified in this research. From Fig. 15, $d / d t\left|\nabla_{p} \ln T_{v}\right|$ for $\mathrm{SB}$ _off is larger than that of SB_on (Figs. 15a,d), and it is mostly contributed by FG2 + FG3
(a)FG1+FG2+FG3+FG4

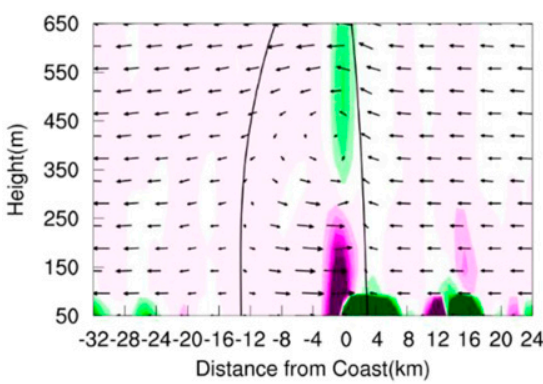

(d)FG1+FG2+FG3+FG4

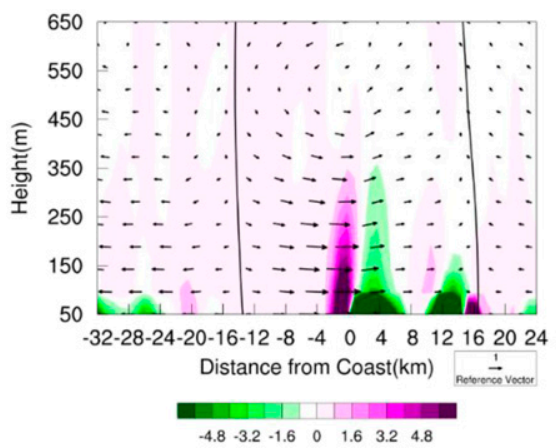

(b)FG1+FG4

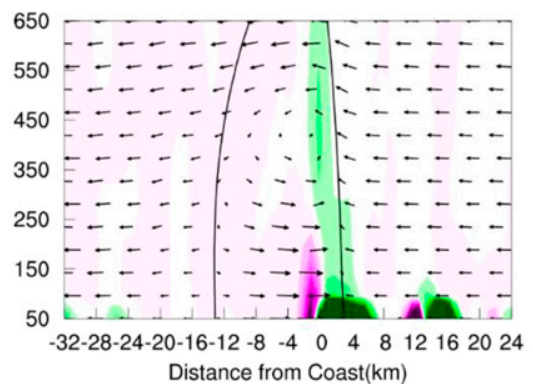
(e)FG1+FG4

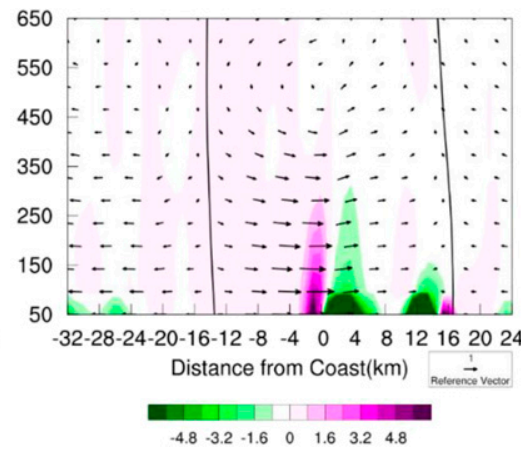

(c)FG2+FG3

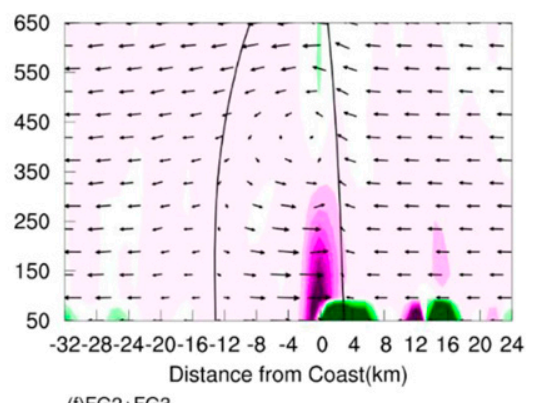

(f)FG2+FG3

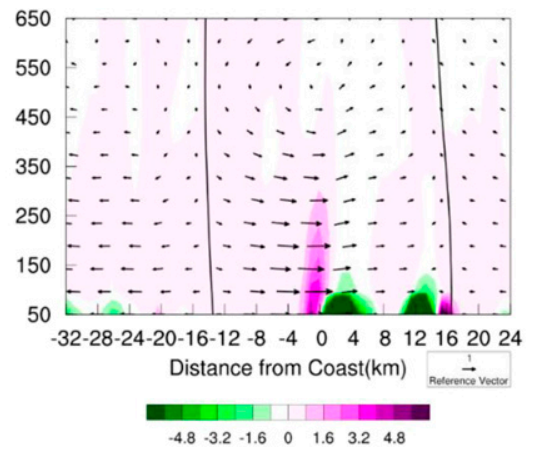

FIG. 15. Yearly averaged (a) FG1 + FG2 + FG3 + FG4, (b) FG1 + FG4, and (c) FG2 + FG3 all overlain with yearly averaged vertical wind fields along coast AG at the strongest time of the sea breeze developed in an offshore background wind (units are $10^{-11} \mathrm{~K} \mathrm{~m}^{-1} \mathrm{~s}^{-1}$ ). (d)-(f) As in (a)-(c), but for the sea breeze developed in an onshore background wind. 
(Fig. 15c). However, the stronger shear of vertical motion in SB_off induces frontolysis above the sea breeze, which may prevent it from developing into the upper levels (Fig. 15a).

\section{Conclusions}

In this study, a new method based on wind decomposition is identified to quantitatively characterize sea breezes in the Pearl River estuary and along the continental coasts in Guangdong, using WRF output data for the whole of 2012. In the PRD region, the sea breeze at coast AG is strongest and also appears most frequently among the three main coasts in the region. It is next strongest in terms of intensity and frequency at coast DE. The yearly variations of sea-breeze intensity and frequency at each coast are quite different from each other. Along coast AG, the sea breeze is comparatively stronger in autumn (September and October) and early spring (January-March), whereas over coast $\mathrm{DE}$, it is more intensive in summer (July and August) and January. The sea-breeze intensity along coast BC does not vary much in 2012, except during one impressive minimum in February. The sea breeze at coast AG occurs most frequently in October. Along the other two coasts, it appears most frequently in July. Although the sea breeze at coast BC is weakest among these three coasts, its inland-penetration distance and pumping ability are greatest, probably due to stronger onshore background winds. In addition, the height of the sea breeze at coast $\mathrm{BC}$ is also the highest in the PRD region. Good linear correlations between the background wind and sea-breeze intensity are found at coasts DE and AG. Because of the influence from estuaries, this correlation is not as good at coast $\mathrm{BC}$.

Sea breezes in the PRD region have similar vertical structures at their start times, strongest times, and end times. The sea breeze along all coasts decreases with height at each moment. The maximum vertical velocity in the convergent zone is located above the top of the sea breeze but below the top of the sea-breeze circulation. From the start time to strongest time, the sea-breeze intensity, its pumping ability, and height, in conjunction with vertical motion in the convergent zone, are apparently enhanced.

In this research, the solenoid term is modified and decomposed into two parts: pressure gradient force and virtual temperature gradient. As the pressure gradient almost remains constant, the solenoid term is mostly modulated by the temperature gradient. The frontogenesis function is utilized to diagnose the dynamic processes of the sea-breeze front and verify the hypothesis that sea-breeze frontogenesis is enhanced by offshore background wind by strengthening the convergence in the frontal head.

Acknowledgments. We thank Dr. Cao Jie (Institution of Atmospheric Physics, CAS) and Prof. Qin Xu (NOAA/ National Severe Storms Laboratory) for providing the source code of wind decomposition. We appreciate the assistance of the Hong Kong Observation (HKO), which provided the meteorological data. This work was supported by NSFC/RGC Grant N_HKUST631/05, NSFCFD Grant U1033001, and the RGC Grant 16303416.

\section{REFERENCES}

Arritt, R. W., 1993: Effects of the large-scale flow on characteristic features of the sea breeze. J. Appl. Meteor., 32, 116-125, https:// doi.org/10.1175/1520-0450(1993)032<0116:EOTLSF > 2.0.CO;2.

Cao, J., and Q. Xu, 2011: Computing streamfunction and velocity potential in a limited domain of arbitrary shape. Part II: Numerical methods and test experiments. Adv. Atmos. Sci., 28, 1445-1458, https://doi.org/10.1007/s00376-011-0186-5.

Ding, A., T. Wang, M. Zhao, T. Wang, and Z. Li, 2004: Simulation of sea-land breezes and a discussion of their implications on the transport of air pollution during a multi-day ozone episode in the Pearl River delta of China. Atmos. Environ., 38, 67376750, https://doi.org/10.1016/j.atmosenv.2004.09.017.

Emery, W. J., D. J. Baldwin, P. Schlüssel, and R. W. Reynolds, 2001: Accuracy of in situ sea surface temperatures used to calibrate infrared satellite measurements. J. Geophys. Res., 106, 2387-2405, https://doi.org/10.1029/2000JC000246.

Finkele, K., J. M. Hacker, H. Kraus, and R. A. D. Byron-Scott, 1995: A complete sea-breeze circulation cell derived from aircraft observations. Bound.-Layer Meteor., 73, 299-317, https://doi.org/10.1007/BF00711261.

Huang, J., J. C. H. Fung, and A. K. H. Lau, 2006: Integrated processes analysis and systematic meteorological classification of ozone episodes in Hong Kong. J. Geophys. Res., 111, D20309, https://doi.org/10.1029/2005JD007012.

Kraus, H., J. M. Hacker, and J. Hartmann, 1990: An observational aircraft-based study of sea-breeze frontogenesis. Bound.-Layer Meteor., 53, 223-265, https://doi.org/10.1007/ BF00154443.

Lam, K. S., T. J. Wang, C. L. Wu, and Y. S. Li, 2005: Study on an ozone episode in hot season in Hong Kong and transboundary air pollution over Pearl River delta region of China. Atmos. Environ., 39, 1967-1977, https://doi.org/ 10.1016/j.atmosenv.2004.11.023.

Liu, S., M. Hu, S. Slanina, L.-Y. He, Y.-W. Niu, E. Bruegemann, T. Gnauk, and H. Herrmann, 2008: Size distribution and source analysis of ionic compositions of aerosols in polluted periods at Xinken in Pearl River delta (PRD) of China. Atmos. Environ., 42, 6284-6295, https://doi.org/ 10.1016/j.atmosenv.2007.12.035.

Lo, J. C. F., A. K. H. Lau, J. C. H. Fung, and F. Chen, 2006: Investigation of enhanced cross-city transport and trapping of air pollutants by coastal and urban land-sea breeze circulations. J. Geophys. Res., 111, D14104, https://doi.org/10.1029/ 2005 JD006837.

Lu, X., K. C. Chow, T. Yao, J. C. H. Fung, and A. K. H. Lau, 2009: Seasonal variation of the land-sea breeze circulation in the 
Pearl River delta region. J. Geophys. Res., 114, D17112, https://doi.org/10.1029/2009JD011764.

Ninomiya, K., 1984: Characteristics of baiu front as a predominant subtropical front in the summer Northern Hemisphere. J. Meteor. Soc. Japan, 62, 880-894, https://doi.org/10.2151/jmsj1965.62.6_880.

Pleim, J. E., 2007a: A combined local and nonlocal closure model for the atmospheric boundary layer. Part I: Model description and testing. J. Appl. Meteor. Climatol., 46, 1383-1395, https:// doi.org/10.1175/JAM2539.1.

__ 2007b: A combined local and nonlocal closure model for the atmospheric boundary layer. Part II: Application and evaluation in a mesoscale meteorological model. J. Appl. Meteor Climatol., 46, 1396-1409, https://doi.org/10.1175/JAM2534.1.

Simpson, J. E., 1994: Sea Breeze and Local Winds. Cambridge University Press, $234 \mathrm{pp}$.

Thompson, W. T., T. Holt, and J. Pullen, 2007: Investigation of a sea breeze front in an urban environment. Quart. J. Roy. Meteor. Soc., 133, 579-594, https://doi.org/10.1002/qj.52.
Wang, T., and J. Y. H. Kwok, 2003: Measurement and analysis of a multiday photochemical smog episode in the Pearl River delta of China. J. Appl. Meteor., 42, 404-416, https://doi.org/10.1175/ 1520-0450(2003)042<0404:MAAOAM>2.0.CO;2.

Wu, M., D. Wu, Q. Fan, B. M. Wang, H. W. Li, and S. J. Fan, 2013: Observational studies of the meteorological characteristics associated with poor air quality over the Pearl River delta in China. Atmos. Chem. Phys., 13, $10755-10766$, https://doi.org/ 10.5194/acp-13-10755-2013.

Xie, B., J. C. H. Fung, A. Chan, and A. Lau, 2012: Evaluation of nonlocal and local planetary boundary layer schemes in the WRF Model. J. Geophys. Res., 117, D12103, https://doi.org/ 10.1029/2011JD017080.

Xu, Q., J. Cao, and S. Gao, 2011: Computing streamfunction and velocity potential in a limited domain of arbitrary shape. Part I: Theory and integral formulae. Adv. Atmos. Sci., 28, 1433-1444, https://doi.org/10.1007/s00376-0110185-6. 